\title{
Effectiveness of the Community Health Nursing Workbook for Notre Dame of Dadiangas University
}

\author{
Ser Rosenkranz Gagnao Espartero*
}

RN Subject Matter Expert Notre Dame of Dadiangas University Marist Avenue, General Santos City, Philippines.

\section{Correspondence:}

Ser Rosenkranz G. Espartero, MAN, RN Subject Matter Expert Notre Dame of Dadiangas University Marist Avenue, General Santos City, Philippines, E-mail: serfranz@yahoo.com.

Received: 04 April 2018; Accepted: 25 April 2018

Citation: Ser Rosenkranz G. Espartero. Effectiveness of the Community Health Nursing Workbook for Notre Dame of Dadiangas University. Nur Primary Care. 2018; 2(2): 1-2.

\begin{abstract}
This research and development study focused on the development, validation, and test of effectiveness of the Community Health Nursing Workbook. It utilized the descriptive - normative survey method in determining the content and validity of the workbook and pre-test and post-test research design in determining its effectiveness as an instructional material for teaching Community Health Nursing (CHN). Two groups participated in the study participated in the study: the first group consisted of 15 participants for the development and validation of the workbook and the second group consisted of 102 second year BS Nursing students who were considered for the experimental procedure of the study.

The validators rated the CHN Workbook as Highly Appropriate, High Comprehensive and Highly Usable. Other results revealed that the enumerated topics in the CHN Workbook were Highly Difficult, and so they should be included. This finding was shared by the Clinical Instructors, under Commission on Higher Education (CHED) Memorandum Order (CMO) \# 30 curriculum. Moreover, the Clinical Instructors perceived that the given topics were extremely needed; therefore these topics should be included in the CHN Workbook per CMO \# 14, series of 2009 curriculum.

The T-test showed that there was significant improvement in learning Community Health Nursing among the student nurses who used the CHN Workbook than those who did not use the CHN Workbook. Based on the findings, the study had drawn out the following conclusions: the topics in the Community Health Nursing are Highly Difficult and this necessitated the development of the CHN Workbook; these topics were also extremely needed per CMO \# 14, series of 2009 curriculum, hence, they must be included in the CHN Workbook. The nursing students who used the CHN Workbook learn more and better than those who did not.

The study recommended that the CHN Workbook may be used not only at Notre Dame of Dadiangas University's (NDDU's) College of Nursing, but also in other Nursing Schools to further establish and strengthen its validity.
\end{abstract}

\section{Keywords}

Community Health Nursing, Workbook, Students.

\section{Introduction}

Traditional nursing pedagogies that use teacher-centered learning approaches have produced efficient, knowledgeable nursing graduates for many years. However, 21 st century learners require and demand new educational approaches [1].
Traditional methods no longer satisfy the demands of neither today's learner nor do they answer health care reforms' continuous calls for nursing innovation. Nurse educators, realizing the constraint of conventional pedagogy, have begun to develop and implement alternative interpretative pedagogies. These nontraditional pedagogies result in a learning climate that is more cooperative an egalitarian. A shift in focus to reflecting, learning, connecting, and thinking with students is therefore occurring [1]. 
Nurse educators are now expected to use creative strategies to educate a post-modern generation of students who possess distinct characteristics, particularly related to teaching and learning [2]. Further explained that the complexity of today's health care system related to changing sociological factors and the difference and the difference in this generation are reasons to tap into the strength of this generation and consider how a post-modern perspective can influence nursing education.

Nurse educators' surveys consistently report that teaching is a source of reward but these educators say that they are working longer hours and dealing with more student groups [3]. At the same time, they still wish to improve and innovate their practice by designing and delivering effective courses like workbook and or modules to maximize the chance that learners will experience coherence, progression and deep learning [4].

Learning styles is all about using the best approach to induce learning [5]. Stated that workbook teach and learning is constructed from a scope and sequence of interrelated topics nested in expository structure. She further stipulated that workbooks are paragons of good teaching, facilitating students' rapid long term acquisition of chapter content. Rather than interrupting and distracting from text, they are embedded in narrative context and bring textual processing to higher cognitive level.

NDDU Clinical Instructors felt the need for a workbook in Community Health Nursing. Having felt the necessity for it also, the researcher considered the idea to develop, validate, and test the effectiveness of the proposed Community Health Nursing workbook as a tool to aid the learning process of the NDDU students.

\section{Methodology}

The study employed descriptive normative surveys and the Research and Development method of research. Pre-test and posttest were conducted to determine the effectiveness of the developed instructional material for teaching the Community Health Nursing. Two groups participated in the study: the first group consisted of 15 participants for the development and validation of the proposed workbook and the second group consisted of 102 second year BS Nursing students who were considered for the experimental procedure of the study. The first group of participants comprised of the Dean of the College of Nursing, the Coordinators, the Clinical Instructors, and an English Consultant. Data gathered were statistically treated using frequency, weighted mean, and T-test for independent samples.

\section{Findings}

The topics in Community Health Nursing revealed an average of 4.26, interpreted as Highly Difficult. Hence, these topics should be included in the Community Health Nursing Workbook. Top on the list is the topic on Family Assessment which obtained the mean of
4.46, and the least on Establishing a Good Relationship with the Community which garnered the mean of 4.05 .

The results of the Clinical Instructors' participants' evaluation showed that, based on their experiences under CMO \# 30 curriculum, the ten topics in Community Health Nursing were generally Highly Difficult and should be included in the Community Health Nursing Workbook.

The data on the perception of Clinical Instructors on what topics were needed in Community Health Nursing based on CMO \# 14, series of 2009 showed that the Clinical Instructors were unanimous with their perception that the ten topics in Community Health Nursing were Extremely Needed and should be included in the Community Health Nursing Workbook. The average mean of 4.64, was interpreted as Very Highly Needed and should be included in the Community Health nursing Workbook. These topics are: Establishing Good Working Relationship, Family Assessment, Family Health Care Planning, Family Health Evaluation, Establishing Good Working Relationship in Community, Community Assessment, Community Health Care, Community Health care Implementation, and Community Health Care Evaluation. This finding revealed that the Clinical Instructors generally perceived that the ten enumerated topics were Extremely Needed and should be included in the Community Health Nursing Workbook based on CMO \# 14, series of 2009.

The validity of the Community Health Nursing Workbook based on three parameters, namely: appropriateness, comprehensiveness, and usability were rated with an average of 4.56, interpreted as High. The Community Health Nursing Workbook was characterized as $81-100 \%$ appropriate, comprehensive and usable.

The mean of the experimental group which used the Community Health Nursing Workbook was significantly higher in the improvement in learning Community Health Nursing than the control group which did not use any Community Health Nursing Workbook. Higher gain scores were obtained and comprehension had taken place among student nurses which used the Community Health Nursing Workbook.

\section{References}

1. Brown ST. A Review of Narrative Pedagogy Strategies to Transform Traditional Nursing Education. Journal of Nursing Education. 2008; 47: 283-286.

2. Archin AO. Using Deconstruction to Educate Generation Y Nursing Students. Journal of Nursing Education. 2007; 46: 562567.

3. McInnis C. Changing Academic Roles The Everyday Realities Challenging Quality in Teaching. Canberra Quality in Higher Education. 2000; 2: 143-152.

4. Knight P. Being a Teacher in Higher Education. 2002.

5. Lepionka ME. Textbook Authorship. Gloucester, MA, USA Atlantic Path Publishing. 2009.

(C) 2018 Filiz, Okur \& Zeynep Güneş. This article is distributed under the terms of the Creative Commons Attribution 4.0 International License 